\title{
PENGARUH TEOLOGI EKARISTI IGNATIUS ANTIOKHIA TERHADAP ENSIKLIK ECCLESIA DE EUCHARISTIA
}

\author{
Yakin Ciptamulya
}

\begin{abstract}
:
In the Encyclical of Ecclesia de Eucharistia, John Paul II states that Eucharist unites Church with God. In Eucharist, the presence of Christ is real. As a consequence, understanding Eucharist as merely series of rubrics is a form of reduction of the Eucharist. In the Encyclical, the Pope recalled the thought of Ignatius of Antioch on the Eucharist. Both John Paul II and Ignatius stated that Eucharist is a thanksgiving on the salvation of God. Eucharist is an invitation of God for the Church to live in the presence of God. The living experience of loving God supports the Church in transforming the world. The Church receives the power of Loving God in the Eucharist that strengthens each witness to live an exemplary Christian life here and now.
\end{abstract}

Kata-Kata Kunci:

Ekaristi, teologi ekaristi, Ensiklik Ecclesia de Eucharistia, Gereja perdana.

\section{PENDAHULUAN}

Pada peringatan pesta perak pontifikatnya, pada hari Kamis Putih tanggal 17 April 2003, Paus Yohanes Paulus II menerbitkan Surat Ensiklik Ecclesia de Eucharistia. Ensiklik ini berisi pandangan yang sangat kaya mengenai Ekaristi dan hubungan dengan Gereja. Satu tahun berselang, Paus Yohanes Paulus II memaklumkan Tahun Ekaristi yang dimulai sejak Oktober 2004 dan diakhiri pada Oktober 2005. Pemakluman Tahun Ekaristi ini ditandai dengan diterbitkannya Surat Apostolik Mane Nobiscum Domine, oleh Paus Yohanes Paulus II. Tahun Ekaristi dibuka secara resmi melalui Kongres Ekaristi Internasional $^{1}$ di Guadalajara, Meksiko tanggal 10 - 17 Oktober 2004, dan diakhiri dengan Sidang Sinode Para Uskup di Roma pada tanggal 2-29 Oktober 2005 yang mengambil tema: Ekaristi Sumber dan Puncak Hidup dan Perutusan Gereja.

Dalam Ensiklik Ecclesia de Eucharistia, Paus Yohanes Paulus II menjelaskan bahwa Gereja hidup dari Ekaristi. Penjelasan ini memperoleh dasarnya dalam ajaran Konsili Vatikan II, bahwa Kurban Ekaristi adalah sumber dan puncak setiap hidup Kristiani. ${ }^{2}$ Yohanes Paulus II menjelaskan bahwa dalam Ekaristi Kudus terkandunglah seluruh kekayaan rohani Gereja, yakni Kristus sendiri, Roti Paskah yang hidup. Lewat tubuh-Nya sendiri, Ia menawarkan hidup-Nya pada manusia.

Sebagai jantung hidup Gereja, Ekaristi menjadi sakramen misteri Paskah, yang dilaksanakan oleh para rasul sejak awal Gereja."Mereka bertekun dalam pengajaran rasul-rasul dan dalam persekutuan. Dan mereka selalu berkumpul untuk memecahkan roti dan berdoa" (Kis 2:42). "Memecahkan roti" memiliki arti merayakan Ekaristi. Oleh karena itu, Yohanes Paulus II mengajak Gereja masa kini untuk kembali menghidupi citra Gereja purba. Bagi Yohanes Paulus II, Gereja dibangun atas 'landasan para Rasul' (Ef 2:20), sebagai saksi pilihan yang diutus mengemban misi oleh Kristus sendiri. Atas dasar tersebut, Ekaristi juga dilandaskan atas para Rasul, ini berarti Ekaristi yang berasal dari Kristus, dipercayakan pada para Rasul untuk disampaikan kepada Gereja melalui para pengganti mereka. Kesinambungan dengan praktek para Rasul inilah yang menjadi kekayaan Gereja yang perlu digali dan dipahami dengan lebih mendalam. 
Dalam kesinambungannya dengan para Rasul, para Bapa Gereja mencoba mengungkapkan dan menjelaskan ajaran para Rasul melalui tulisantulisannya.Tulisan para Bapa Gereja mempunyai bobot yang dapat dipercaya dan ditinggikan, karena mereka masih memiliki kedekatan dengan para Rasul. Maka, sesudah Kitab Suci, tulisan mereka menjadi sumber paling asli dalam mengenal alam pikiran umat Kristiani pertama secara lebih mendalam. Para Bapa Gereja mempunyai peranan fundamental dalam kaitannya dengan tradisi yang hidup terus-menerus, mendampingi dan membimbing Gereja. Di dalam arus tradisi besar ini, sumbangan khusus dari patristik didapat dengan menyimpulkan sebuah orientasi dasar yang membentuk tradisi doktrinal Gereja atas keseluruhan Kitab Suci, dan menyediakan suatu pengajaran teologis yang kaya untuk instruksi dan pemeliharaan rohani orang beriman. Kekayaan teologis dari ajaran Patristik, selain dikaitkan dengan pemahaman tentang Kitab Suci, seperti homili dan komentar, juga kelihatan dalam karya-karya teologis dalam rangka perdebatannya dengan ajaran sesat. Para Bapa Gereja sungguh menampilkan semangat Kristiani yang otentik, yang menjadi bagian dari tradisi Gereja yang hidup.

Ajakan Yohanes Paulus II, dalam Ecclesia de Eucharistia, untuk kembali menggali kekayaan rohani Gereja perdana menjadi tanda bahwa ada kesinambungan pengajaran dari para Rasul, Bapa Gereja hingga zaman sekarang.Atas dasar tersebut, penulis mencoba menggali hubungan atau pengaruh ajaran Bapa Gereja terhadap Ensiklik Ecclesia de Eucharistia. Dalam ensiklik ini, ada beberapa nama dari Bapa Gereja yang disebut, antara lain: St. Ambrosius dari Milano, St. Yohanes Krisostomus, St. Efrem, St. Cyrilius dari Alexandria, dan St. Ignatius dari Antiokhia. Dari kelima Bapa Gereja ini, St. Ignatius dari Antiokhia-lah yang merupakan Bapa Gereja tertua.

St. Ignatius yang dikenal dengan nama Theophorus, ${ }^{3}$ hidup sekitar tahun 35-107 M, kemungkinan ia berasal dari Siria. Menurut tradisi, Ignatius adalah uskup di Antiokhia, murid Rasul Yohanes. Dia diangkat menjadi uskup Antiokhia menggantikan Petrus sebagai uskup kedua, ${ }^{4}$ demikian menurut Origenes dan Eusebius. Tetapi ada juga yang berpendapat bahwa Ignatius adalah uskup yang ketiga, ia menggantikan Evodius. ${ }^{5}$ Pendapat lain lagi mengatakan, bahwa di Antiokhia terdapat dua orang uskup, yaitu Evodius yang diangkat oleh Petrus sebagai uskup atas orang Kristen asal Yahudi sedangkan Ignatius adalah uskup atas orang Kristen kafir yang diangkat oleh Paulus. ${ }^{6}$ Ignatius sendiri tidak pernah mengungkapkannya dalam surat-suratnya. Sebagai seorang Uskup, Ignatius juga dipercaya termasuk orang Kristen generasi pertama, orang yang telah mengenal Kristus, dan mendapat pengajaran langsung dari para Rasul.

Kesaksian Ignatius dari Antiokhia sangat penting bagi kehidupan Gereja, bahkan di zaman sekarang ini. Ignatius memberikan kesaksiannya pada titik balik sejarah, saat aktivitas dalam penemuan dan pengembangan pemikiran Kristen sedang dirintis. Dia juga terlibat dalam perkembangan kehidupan liturgi dan pengorganisasian umat. Ajaran sesat, doketisme, merebak dan membingungkan iman umat akan kemanusiaan Kristus. Namun kesulitan dan ancaman tidak menghentikan gerak maju Gereja, bahkan memperkuat identitasnya sehingga mampu untuk menerobos batas penghalang, dalam rangka untuk membawa Injil kepada bangsa-bangsa di dunia. Ini adalah konteks di mana Ignatius dari Antiokhia hidup.

Selain itu, penulis melihat bahwa teologi Ekaristi dari Ignatius memiliki keselarasan dengan Ensiklik Ecclesia de Eucharistia. Selain menekankan Ekaristi sebagai kurban, obat keabadian, kehadiran real dari Kristus, Ignatius juga menekankan hubungan antara Ekaristi dengan praksis hidup Gereja. Ignatius mengajarkan bahwa Ekaristi menghantarkan Gereja pada persatuan dengan Allah dalam Kristus serta mengerakkan umat untuk bersatu dalam Gereja dibawah kepemimpinan Uskup, sebagai wakil Allah. Persatuan ini diungkapkan secara nyata melalui keberanian untuk menjadi martir Kristus.

Tidak ada seorangpun di antara Bapa-bapa Gereja yang mengungkapkan keinginan akan persatuan dengan Kristus dan hidup dalam Dia dengan begitu mantap seperti Ignatius. Kerinduan Ignatius yang tak tertahankan akan persatuannya dengan Kristus merupakan dasar bagi suatu "mistik persatuan” yang sejati dan asli. ${ }^{7}$ Kesatuan itutampak dalam cara hidupnya hingga akhir. ${ }^{8}$ Sebagai “Guru Kesatuan”, Ignatius mengundang umat beriman untuk mensintesiskan penghayatan akan Ekaristi (sebagai lambang yang nyata akan persatuan dengan Kristus $^{9}$ ) dengan dedikasi kepada Gereja-Nya (persatuan dengan Uskup, para Imam dan Diakon serta seluruh umat beriman ${ }^{10}$ ). Ignatius sebagai Uskup telah menghantar orang pada suatu kesatuan antara communio dan missio. ${ }^{11}$ 


\section{LATAR BELAKANG SEJARAH DAN PEMIKIRAN DARI IGNATIUS ANTIOKHIA}

Hidup dan karya Ignatius berlangsung selama 72 tahun. Di akhir masa hidupnya, saat perjalanan menuju Roma untuk menjadi martir, Ignatius menulis ketujuh suratnya: Efesus, Tralles, Magnesia, Roma, Philadelphia, Smyrna dan kepada Polycarpus di Smyrna.

Sebagai murid dari Rasul Yohanes dan Paulus, Ignatius mampu menyintesiskan pandangan dari kedua gurunya ke dalam ajarannya tentang kesatuan. Sebagai uskup di Antiokhia, tema kesatuan, baik yang bersifat teologis maupun eklesial, menjadi perhatian pokok dalam hidup dan pemikiran Ignatius.Baginya kesatuan dengan Allah dalam diri Kristus menjadi dasar/penopang bagi terbentuknya kesatuan Gereja. Kesatuan Gereja sendiri hanya mungkin terwujud dalam persatuan dengan uskupnya karena tanpa uskup tidak akan ada Gereja yang sah. Uskup dipandang sebagai guru iman; pemimpin umat; pelayan liturgi; dan penjaga serta pembela kesatuan Gereja. Oleh sebab itu, Ignatius sekuat tenaga melawan perpecahan yang ada pada Gereja saat itu, akibat dari ajaran Doketisme.

Dalam surat-surat Ignatius dapat ditemukan pelbagai dialektika yang kaya dan saling berhubungan antara dua segi khas kehidupan Kristiani: di satu pihak tentang kesatuan dasariah yang mengikat semua orang beriman di dalam persatuannya dengan Kristus, dan di pihak lain tentang struktur hierarkis dalam komunitas Gereja. Kedua hal itu tidak saling bertentangan, sebaliknya saling melengkapi dan menyempurnakan. Itulah sebabnya, Ignatius dijuluki "Guru kesatuan” yang mengundang semua orang Kristiani untuk mensistesiskan imannya. Perjuangan dalam mencapai persatuan ini hanya mungkin terwujud dalam kesatuan dengan Allah dan Gereja, yang secara simbolis dan riil terpenuhi dalam perayaan Ekaristi yang dipimpin oleh uskup, yang merupakan representasi dari Allah sekaligus Gereja.

\section{TEOLOGI EKARISTI DARI IGNA- TIUS ANTIOKHIA}

Ignatius dalam surat-suratnya berusaha menunjukkan pada umat bagaimana jalan untuk mencapai persekutuan dengan Allah. Persatuan dalam perayaan Ekaristi yang dipimpin oleh uskup (atau orang yang diberi kuasa olehnya) menjadi sarana yang ditawarkan oleh Ignatius. Dalam suratsuratnya, Ignatius menunjukkan kekayaan makna dan spiritualitas Ekaristi yang dapat ditimba dan diterima oleh umat. sungguh menjadi tanda kesatuan Gereja yang memungkinkan orang-orang beriman untuk mencapai Allah melalui Kristus.

Ignatius sungguh prihatin terhadap kesesatan yang dapat menjauhkan umat dari Allah dan yang menyebabkan perpecahan dalam Gereja. Kesesatan yang diakibatkan oleh ajaran dari para guru palsu. Untuk itulah Ignatius menyerukan umat untuk bersatu dalam Ekaristi, sebagai sarana untuk mengalahkan kesesatan setan.

Ekaristi menjadi unsur paling penting dalam kehidupan Gereja. Sebagai daging dan darah Kristus, yang adalah "satu-satunya dokter jasmani dan rohani”, ${ }^{12}$ Ekaristi akan menyatukan umat beriman dengan Kristus, yang sudah selalu bersatu dengan Bapa, dan dengan seluruh Gereja, (uskup, imam, diakon, dan seluruh umat). Melalui Ekaristi umat beriman akan diangkat dan diikut-sertakan dalam persekutuan abadi Allah Tritunggal. Ekaristi sebagai daging dan darah Kristus merupakan "obat keabadian", 13 yang sanggup menawarkan kematian dan menganugerahkan kehidupan abadi.

Setiap kali jemaat memakan roti dan meminum anggur dari cawan Ekaristi, mereka menyatakan kebangkitan Kristus, sebab dalam Ekaristi kita memakan Kristus yang bangkit. Ignatius juga mengaitkan Ekaristi dengan kurban Kristus dan kemartiran, sebagai antisipasi terhadap kemartirannya sendiri. Kurban dan kemartiran dipandang sebagai masa lalu dan masa yang akan datang, "Ekaristi sebagai kurban dan kemartiran adalah bagian dari masa lalu dan masa depan”. ${ }^{14}$ Berbagi Ekaristi berarti berbagi kesatuan dengan Kristus, dalam Bapa, yang terlaksana di dalam Gereja-Nya. Untuk Ignatius, Ekaristi menjadi satu-satunya cara untuk menjalin kesatuan dengan Allah. Akhirnya kita dapat mengatakan sesuai dengan surat Ignatius bahwa Ekaristi adalah makanan yang benar bagi umat Kristiani, yang mengakui keilahian dan kemanusiaan Kristus, dengan cara menerima daging dan darahNya dalam Ekaristi.

\section{TEOLOGI EKARISTI DARI YOHANES PAULUS II DALAM ECCLESIA DE EUCHARISTIA}

Meskipun ensiklik ini bukanlah sebuah risalah lengkap tentang Ekaristi, namun Ecclesia de Eucharistia (selanjutnya: EE) mengandung pokok-pokok ajaran Gereja mengenai Ekaristi. Ensiklik yang kaya akan nilai spiritual dan teologis ini menfokuskan diri pada pembahasan 
tentang Ekaristi dan hubungannya dengan Gereja. Dalam EE, Bapa Suci berusaha menunjukkan pada Gereja bagaimana caranya mengalami sukacita pemenuhan janji Tuhan: "Lihatlah, Aku akan beserta kamu sampai akhir zaman” (Mat 28:20). Dalam Ekarisi Kuduslah, lewat pengubahan roti dan anggur menjadi tubuh dan darah Tuhan, Gereja bersukacita atas kehadiran-Nya yang maha pekat (EE 1). Demikianlah Gereja selalu mengarahkan pandangannya kepada Tuhan, yang hadir dalam Sakramen Ekaristi. Di sanalah Gereja menemukan kepenuhan pernyataan kasih-Nya yang tak terbatas. Hal ini ditegaskan kembali pada akhir EE, dengan mengutip Surat Apostolik Novo Millennio Ineunte, Sri Paus menunjukkan apa yang harus menjadi kekuatan dalam menepuh seluruh perjalanan hidup Gereja dan dunia pada milenium ketiga ini. Programnya sudah ada dan jelas, yakni berpusat pada pribadi Kristus, sebagaimana termaktub dalam Injil dan Tradisi. Tujuannya jelas, yaitu agar dapat menghayati hidup Tritunggal Mahakudus, dan bersama Dia mengubah sejarah hingga penggenapannya di dalam Yerusalem Surgawi (NMI 29).Perwujudan program ini hanya berlangsung lewat Ekaristi."Dalam Ekaristi, kita menemukan Yesus; menerima kurban penebusanNya; mendapat kebangkitanNya; menyambut karunia Roh Kudus; menyembah, menaati dan mengasihi Bapa” (EE $60)$.

Yohanes Paulus II sungguh prihatin terhadap keredupan di beberapa tempat, di mana terjadi penyalahgunaan yang dapat membingungkan iman umat akan ajaran Katolik yang benar tentang Ekaristi: praktek sembah sujud Ekaristi yang hampir terlupakan sama sekali; terjadinya pemiskinan yang hebat terhadap pemahaman akan misteri Ekaristi; makna kurban Ekaristi dilucuti dan hanya dilihat sebagai perjamuan persaudaraan semata; pelayanan imamat, yang didasarkan pada kesinambungan apostolik, menjadi redup; dan hakikat sakramental dari Ekaristi dipersempit hanya pada daya gunanya sebagai salah satu pewartaan (EE 10). Ekaristi adalah karunia yang terlalu berharga untuk diserahkan kepada ketidaktentuan dan pelecehan. Untuk itulah, ensiklik ini ditulis, agar dapat menghapus awan kelam pada ajaran dan praktek yang harus ditolak, sehingga Ekaristi terus bersinar dalam seluruh misterinya yang cemerlang. Ekaristi tidak lain adalah secercah penampakan surga di atas bumi. Ekaristi seberkas sinar mulai dari Yerusalem surgawi yang menembus awan sejarah dan menerangi peziarahan kita (EE 19). Ditegaskan sekali lagi, bahwa Ekaristi sungguh menjadi khazanah maha berharga: bukan hanya dengan merayakannya tetapi juga dengan berdoa di hadapannya di luar Misa ( $E E$ 25). Ekaristi harus dialami dan dihayati dalam integritasnya, baik dalam perayan maupun dalam kemesraan dialog dengan Yesus, baik yang terjadi dalam Misa atau penyembahan Ekaristi di luar Misa.

Di bab terakhir dari $E E$, Bapa Suci mengajak seluruh anggota Gereja untuk belajar pada sekolah para kudus, penafsir agung kesalehan Ekaristi sejati. Di atas segalanya, seluruh umat beriman harus belajar pada sekolah Maria. Belajar dari Maria yang menghidupi iman Ekaristinya bahkan sebelum penetapan Ekaristi, sejak dia mempersembah-kan rahim perawannya kepada Penjelmaan Sabda Allah (EE 55). Maria yang selalu hadir bersama Gereja dan sebagai Bunda Gereja, pada setiap perayaan Ekaristi. Untuk itulah, kita diajak untuk meneladan sikap Maria, belajar daripadanya dalam Sekolah Maria. Pada Sekolah Maria, Gereja tidak akan pernah kehilangan salah satu keajaiban dari misteri iman terbesar, yaitu Ekaristi Kudus. Merenungkan Wajah Kristus dalam Ekaristi Kudus melalui mata Maria, Bunda-Nya dan Bunda Gereja. Sekolah Maria menjadi tempat misteri Ekaristi menampakkan diri, lebih pada diri siapapun juga, sebagai misteri Terang. Kagum akan Maria, kita menjadi sadar bahwa daya pembaruan terdapat dalam Ekaristi (EE 62).

\section{SUMBANGAN IGNATIUS ANTIOK- HIA BAGI TEOLOGI EKARISTI YOHANES PAULUS II DALAM EN- SIKLIK ECCLESIA DE EUCHARIS- TIA}

Teologi Ekaristi dari Ignatius Antiokhia memiliki pengaruh dalam pandangan Yohanes Paulus II tentang Ekaristi. Pengaruh ini merupakan bukti dari kesinambungan ajaran Bapa Suci dengan para Rasul, di mana Ignatius sendiri merupakan murid langsung dari Rasul Yohanes dan Paulus. Sedikitnya ada 3 tema besar yang ditemukan penulis, terkait dengan teologi Ekaristi dari kedua tokoh ini, yaitu: Ekaristi sebagai kurban; Ekaristi sebagai kehadiran real dari Kristus; dan Ekaristi dan persatuan iman. Inilah alasannya mengapa Yohanes Paulus II mengajak Gereja masa kini untuk kembali menghidupi citra Gereja purba (EE 3). Kesinambungan dengan praktek para Rasul inilah yang menjadi kekayaan Gereja yang perlu digali dan dipahami dengan lebih mendalam. Itulah sebabnya, tidak sedikit tulisan para bapa Gereja, dalam hal ini Ignatius dari Antiokhia, yang dijadikan sumber referensi Gereja pada masa kini. Ge-reja 
menganggap bahkan meyakini, bahwa sesudah Kitab Suci, tulisan bapa-bapa Gerejalah yang dapat dijadikan sumber paling asli dalam mengenal situasi dan penghayatan umat kristiani pertama secara lebih mendalam.

Ignatius sungguh mempunyai peranan fundamental dalam kaitannya dengan usaha menghidupi, mendampingi dan membimbing Gereja dalam menjaga dan meneruskan tradisi para rasul. Dari pembelajaran mengenai teologi Ekaristi Yohanes Paulus II, kita menemukan bahwa tidak sedikit masalah-masalah aktual Gereja masa kini telah dibahas, walau masih sangat sederhana, dalam tulisan-tulisan Ignatius. Sumbangan khas Ignatius tertuang dalam buah penanya dapat menjadi acuan bagi orientasi dasar dalam pembentukan tradisi doktrinal Gereja selanjutnya. Ignatius, bukan saja menyediakan suatu pengajaran teologis yang kaya dalam instruksi dan pemeliharaan rohani orang beriman, namun juga sungguh menampilkan semangat Kristiani yang autentik, yang menjadi bagian dari tradisi Gereja yang hidup.

\section{PENUTUP}

Tradisi Perayaan Ekaristi sudah setua keberadaan Gereja. Bila Gereja dibangun atas landasan para Rasul, ${ }^{15}$ begitupun Ekaristi yang juga dilandaskan atas para Rasul, yang telah diteruskan oleh para pengganti mereka kepada kita. Dalam usaha menjaga tradisi Ekaristi yang sesuai dengan iman apostolik itulah, Gereja, dalam perjalanan waktu, selalu mencoba untuk mempertahankan serta mengembangkan ajarannya mengenai Eka-risti, termasuk peristilahan yang khas. Dalam kesinambungan, kontinuitas dan diskontinuitas, dengan praktek para Rasul inilah, Gereja mera-yakan Ekaristi sepanjang masa.

Pembahasan tentang tema-tema teologi Ekaristi Ignatius Antiokhia dalam pandangan Yohanes Paulus II, telah membuktikan adanya pengaruh pemikiran Ignatius kepada teologi Ekaristi dari Bapa Suci, khususnya yang termuat dalam $E E$. Pengaruh pandangan ini, nampak dalam kesinambungan, kesamaan dan perkembangan, teologi Ekaristi dari Ignatius kepada Sri Paus. Atas dasar ini, penulis memberanikan diri untuk mengajak para pembaca menimba kembali pemikiran Ekaristi dari para Bapa Gereja, khususnya dari Ignatius. Penulis berpendapat bahwa pandangan Ekaristi dari Ignatius dapat dijadikan dasar bagi teologi dan pastoral Ekaristi di masa sekarang.

Pada bab penutup ini, penulis akan menunjukkan kesimpulan dan relevansi teologi Ekaristi Ig- natius bagi teologi dan pastoral Ekaristi pada masa kini. Kemudian bab ini akan ditutup dengan tanggapan.

\subsection{Kesimpulan}

Hipotesa pada awal karya tulis ini adalah membuktikan adanya kesinambungan antara teologi Ekaristi Ignatius dengan Yohanes Paulus II. Melalui pembahasan surat-surat Ignatius dan ensiklik Ecclesia de Eucharistia dari Yohanes Paulus II, penulis menyimpulkan bahwa ada kesinambungan, yang nampak melalui adanya kesamaan sekaligus perkembangan ide tentang Ekaristi dari Ignatius kepada Yohanes Paulus II. Pernyataan tesis ini dapat dibuktikan dengan beberapa dasar dan kesimpulan sebagai berikut:

6.1.1. Kesinambungan teologi Ekaristi dari Ignatius kepada Yohanes Paulus II nampak melalui dicantumkannya nama Ignatius Antokhia dalam beberapa artikel dari Ecclesia de Ecuharistia. Sedikitnya ada dua artikel yang merujuk secara langsung kepada Ignatius, yaitu artikel 18 terkait dengan Ekaristi sebagai obat keabadian dan artikel 39 mengenai tema Ekaristi sebagai kesatuan iman.

6.1.2. Dalam penelitian lebih lanjut, penulis menemukan sedikitnya ada tiga tema dari teologi Ekaristi yang sama-sama menjadi perhatian dari kedua tokoh ini, antara lain: Ekaristi sebagai kurban; Ekaristi sebagai kehadiran real Kristus; dan Ekaristi sebagai persatuan iman, yang di dalamnya terungkap dimensi teologal, yaitu Ekaristi sebagai sarana persatuan umat dengan Allah dalam dan bersama Kristus, serta dimensi eklesial, yaitu Ekaristi sebagai sarana persatuan Gereja. Melalui kesinambungan ini penulis menemukan alasan mengapa Yohanes Paulus II dalam Ecclesia de Eucharistia artikel 3 mengajak Gereja masa kini untuk kembali menghidupi citra Gereja purba.

6.1.3. Kesinambungan iman akan Ekaristi yang terungkap melalui praktek yang dilakukan oleh para Rasul dan coba dirangkum dalam diktat teologis oleh para Bapa Gereja sungguh nampak dalam pemikiran kedua tokoh ini. Hal ini menjadi kekayaan yang perlu digali dan dipahami dengan lebih mendalam. Itulah sebabnya, selain Kitab Suci, tulisan para Bapa Gereja, dalam hal ini Ignatius dari Antiokhia, dapat menjadi sumber referensi yang paling awal dan asli 
dalam mengenal situasi dan penghayatan umat kristiani pertama. Ignatius memberikan kesaksiannya pada titik balik sejarah, saat aktivitas dalam penemuan dan pengembangan pemikiran Kristen sedang dirintis. Dia juga terlibat dalam perkembangan kehidupan liturgi dan pengorganisasian umat. Teologi Ekaristi dari Ignatius, yang tertuang dalam surat-suratnya, memiliki peran yang penting dalam rangka menjaga dan terus menghidupi tradisi para Rasul. Oleh karena itu, melalui ulasan dalam EE dari Yohanes Paulus II, kita dapat menemukan bahwa tidak sedikit tulisan-tulisan Ignatius yang telah membahas masalah-masalah aktual Gereja pada masa kini, walau masih sangat terbatas dan sederhana. Tulisan inilah yang menjadi acuan dalam pembentukan tradisi doktrinal Gereja selanjutnya. Dapat disimpulkan bahwa Ignatius sungguh berhasil bukan hanya dalam menyampaikan pengajaran teologis yang kaya, namun juga dalam menampilkan semangat kristiani yang autentik, yang menjadi bagian dari tradisi Gereja.

6.1.4. Melalui penelitian ini, penulis menemukan benang merah yang terangkai antara teologi Ekaristi Gereja perdana dengan masa kini. Penemuan ini melahirkan harapan dalam diri penulis agar Gereja dapat semakin diyakinkan akan kesinambungan ajaran Ekaristi sejak Gereja perdana hingga masa kini. Keyakinan ini menjadi pintu masuk bagi Gereja, hierarki maupun umat, agar tidak ragu-ragu lagi menimba dan mengali ajaran Ekaristi dari para Bapa Gereja. Melalui hasil dari penelitian ini, kita bukan hanya berhenti pada pembuktian akan kesinambungan pandangan dari kedua tokoh, namun juga dapat menemukan pencerahan dan pembelajaran tentang refleksi iman akan Ekaristi sepanjang segala masa, mulai dari Gereja perdana, dan menjadi landasan dan penerang bagi Gereja masa kini, serta pembentuk visi bagi Gereja di masa mendatang. Gereja disadarkan bahwa kekayaan dan kedalaman Ekaristi bukan semata diperoleh dari pengetahuan dan pemahaman akan rubik/aturan, melainkan misteri Ekaristi hanya dapat dihayati dalam terang iman, yang mana tradisi menjadi salah satu referensi iman akan Ekaristi, selain Kitab Suci dan magisterium.

\subsection{Relevansi Teologi Ekaristi dari Ignatius dan Yohanes Paulus II bagi Gereja di Masa Kini}

Semua dasar ajaran Ekaristi, baik yang disampaikan oleh Bapa Gereja maupun paus dan para teolog sebenarnya bersumber dari tulisan Perjanjian Baru. Namun masing-masing dari mereka, mengembangkan teologinya sendiri sesuai dengan kebutuhan umat dan bidang yang mereka minati. Interese teologis ini biasanya terkait dengan situasi dan tantangan yang mempengaruhi zaman di mana mereka hidup. Dalam usaha mengadopsi dan mengembangkan ajaran Ekaristi, yang sesuai dengan kondisi zamannya, kita dapat belajar dari usaha mereka, khususnya Ignatius dan Yohanes Paulus II, dalam menemukan dasar teologi dan pastoral Ekaristi. Usaha yang bukan saja berpengaruh pada masanya, namun juga tetap mampu berbicara hingga saat ini.

\subsubsection{Sumbangan Pemikiran Ignatius dan Yohanes Paulus II bagi Dasar Teologi Ekaristi}

Sebagai murid dari Rasul Yohanes dan Paulus, Ignatius telah berhasil menyatukan kedua pandangan gurunya ini dalam satu tema kesatuan. Kesatuan teologis dengan Allah disempurnakan dengan perayaan Ekaristi yang dirayakan oleh seluruh Gereja, umat bersama dengan uskupnya. Uskup menjadi representasi dari Allah $^{16}$ dan Gereja. ${ }^{17}$ Tanpa uskup, Gereja tidak dapat berbuat apa-apa. ${ }^{18}$ Dengan menyintesiskan ke dua ajaran dari Rasul Yohanes dan Paulus, menurut Schoedel, Ignatius mampu mengangkat tema persatuan yang lebih utuh dan sempurna. ${ }^{19}$

Begitupun dengan Yohanes Paulus II, yang terkenal sebagai paus yang memiliki devosi kepada Sakramen Maha Kudus ini. Bagi Bapa Suci, Ekaristi sungguh menjadi jantung yang menghidupi Gereja. Ekaristi dan Gereja saling terkait satu sama lain. Tanpa Ekaristi yang dilaksanakan oleh uskup dan para imam yang dikuasakan, Gereja akan musnah; sedang tanpa Gereja, uskup dan para imam beserta umat, Ekaristi tidak dapat terlaksana. "Ekaristi membangun Gereja dan Gereja mengampuhkan Ekaristi.,"20

Banyak hal yang masih relevan, yang bisa dipelajari dan dikembangkan, dari teologi Ekaristi Ignatius Antiokhia dan Yohanes Paulus II ini. Relevansi ini terlihat melalui banyaknya tematema Ekaristi yang masih menjadi topik pembicaraan terkait dengan teologi Ekaristi 
hingga saat ini, mulai dari Ekaristi sebagai kurban; Ekaristi sebagai kehadiran real dari Kristus; Ekaristi dan perwujudan dari kesatuan iman, baik kepada Allah maupun dengan Gereja.

Dalam tema Ekaristi sebagai kurban, kedua tokoh ini berpijak pada keyakinan akan Kristus yang menyerahkan diri-Nya sebagai Kurban pemulih, kurban inilah yang dirayakan kembali dalam Perayaan Ekaristi. Itulah sebabnya daging Kristus pada kurban salib dan daging pada kurban Ekaristi adalah daging yang satu dan sama. Hal yang senada kembali didengungkan 19 abad kemudian, dalam Konsili Vatikan II diungkapkan bahwa peristiwa kurban salib Kristus itu dirayakan dan dihadirkan pada setiap Perayaan Ekaristi. Kurban Ekaristi ditetapkan untuk "mengabdikan kurban salib untuk selamanya” (SC 47/EE 11).

Pembahasan mengenai Ekaristi sebagai kehadiran real dari Kristus, mengantar kita pada iman Ignatius maupun Bapa Suci, yang meyakini bahwa Kristus yang bangkit dan menampakkan diri pada para murid-Nya, hadir dalam seluruh kedaging-an-Nya, sebagaimana Kristus yang lahir ke dunia ini sebagai manusia penuh. Tujuan Ignatius menekankan ke-daging-an Kristus adalah, selain melawan kaum doketis, juga menyatakan bahwa Kristus yang dapat diinderai oleh para rasul, tetap mampu diinderai oleh kita dalam Perayaan Ekaristi. Melalui roti dan anggur yang telah dikonsekrir, Kristus hadir sepenuhnya, tubuh dan darah-Nya. Itulah sebabnya, Ignatius memandang Ekaristi sebagai sakramen tubuh dan darah Tuhan, di mana Ekaristi sungguh menjadi karunia Kristus yang menghidupkan (Smyrna III).Tema ini tetap aktual hingga saat ini, terlebih sejak abad ke-13 di mana istilah transubstansiasi digunakan.

Tema kesatuan teologis dan eklesial menjadi tema sentral dalam teologi Ignatius yang juga diamini oleh Yohanes Paulus II.Ignatius menjadikan kesatuan dengan Allah Tritunggal sebagai dasar bagi persatuan dengan dan dalam Gereja. Persatuan ini dikukuhkan dalam Perayaan Kasih yang berpuncak pada Ekaristi Kudus, sebagai pemberian diri Allah dalam Kristus kepada umat-Nya, yang dianugerahkan melalui Gereja-Nya. Point inilah yang kembali dinyatakan oleh Yohanes Paulus II dalam EE artikel 23: "Persekutuan Ekaristi juga meneguhkan Gereja dalam kesatuan sebagai tubuh Kristus .... Sedemikian rupa sehingga kita semua dipersatukan satu sama lain dan bersama-sama dipersatukan dengan Kristus”.

Pembahasan terhadap tema di atas membawa pada pengungkapan akan kekayaan dimensi dari teologi Ekaristi Ignatius dan Yohanes Paulus II, mulai dari sisi kristologi, eklesiologi, soteriologi dan eskatologi. Dimensi kristologis nampak melalui penekanan mereka terhadap Ekaristi yang merupakan daging Yesus Kristus, yang menderita akibat dosa kita, yang karena kebaikan-Nya dibangkitkan Bapa dari kematian. ${ }^{21}$ Kita tidak bisa memisahkan realitas daging Kristus dalam inkarnasi dan realitas daging-Nya dalam Ekaristi. Aspek eklesiologis terlihat melalui paham kesatuan Gereja, umat dengan uskupnya dalam merayakan satu Ekaristi, yang adalah satu daging Kristus dan satu piala darah-Nya ${ }^{22}$. Sisi soteriologis terungkap melalui rahmat kehidupan kekal dalam Kristus yang dianugerahkan Allah dalam Ekaristi yang merupakan obat keabadian, penangkal kematian. ${ }^{23}$ Sedangkan klaim eskatologis diungkapkan melalui iman akan sifat dari daging Kristus yang tidak berubah mulai dari peristiwa inkarnasi, sengsara, wafat, dan kebangkitan-Nya hingga saat ini dan sampai kedatangan Kristus yang ke dua kalinya dalam rupa daging yang mulia. ${ }^{24}$

Nampak pengaruh teologi Ignatius terhadap Yohanes Paulus II, yang masih bergema hingga saat ini. Oleh sebab itulah, Bapa Suci mengajak Gereja masa kini untuk mengali kembali teologi Ekaristi dari Bapa-bapa Gereja, khususnya Ignatius, agar dapat dijadikan dasar bagi teologi Ekaristi masa kini, tentu dengan tetap memperhatikan perkembangan waktu, tempat dan sosial budaya yang ada, sehingga kesinambungan yang ada selaras dengan tuntutan zaman. Perkembangan (diskontinuitas) dalam rumusan dan istilah menjadi hal yang diperlukan, bukan saja untuk menjaga kontinuitas iman apostolik akan Ekaristi, namun juga agar dapat melahirkan teologi Ekaristi yang kontekstual. Melalui teologi Ekaristi yang berorientasi pada kehidupan Gereja yang konkrit (kontekstual sekaligus Kristiani), diharapkan teologi lebih mampu memberikan andil bagi penghayatan iman umat akan Ekaristi.

\subsubsection{Pandangan Ignatius bagi Pendasaran Pastoral Ekaristi}

Sebagai seorang uskup, Ignatius terus berjuang dalam menjaga kesatuan umatnya dari pelbagai ancaman yang mampu memecah belah kesatuan jemaat. Dapat dikatakan bahwa pastoral Ekaristi dari Ignatius lahir dari pengalaman konkritnya dalam menanggapi praksis hidup jemaat pada zamannya. Pengalaman real tersebut kemudian dibaca dalam perspektif iman dengan berlandaskan pada Kitab Suci dan aneka tradisi lisan serta tulisan, yang menghasilkan ekspresi iman 
dalam praksis liturgi dan pastoral yang sesuai dan mampu menjawab pelbagai kebutuhan jemaat pada zamannya. Itulah sebabnya, praksis liturgi dan pastoral yang digali dari pengalaman real umat dan telah dimurnikan melalui kesesuaian dengan ajaran iman dari para Rasul, lebih dapat diterima dan bertahan serta memiliki daya, bukan saja bagi umat pada zamannya namun juga melampaui masanya.

Menghadapi ancaman perpecahan yang disebabkan oleh pelbagai ajaran sesat, doketisme dan yudaisme, Ignatius, tanpa jemu, terus mengingatkan umatnya akan pentingnya kesatuan hati dan pikiran ${ }^{25}$ dengan uskup ${ }^{26}$. Kesatuan ini hanya dapat terlaksana melalui praksis hidup yang dilakukan terus-menerus.Oleh sebab itu, Ignatius menekankan pentingnya umat untuk berkumpul bersama, sesering mungkin, dalam Perayaan Ekaristi. ${ }^{27}$ Melalui habitus kebersamaan yang dibangun terus-menerus, Ignatius mengajak umatnya untuk bersatu dalam membangun Gereja dan memuliakan Tuhan. ${ }^{28}$

Bagi Ignatius, Perayaan Ekaristi bukan saja sebagai ungkapan dan perayaan iman, melainkan juga menjadi realisasi dari usaha pastoral Ekaristi itu sendiri. Itulah sebabnya, mengapa Ignatius mampu menghubungkan Ekaristi dengan tematema yang bernada pastoral: dari Ekaristi menuju ke kemartiran dan dari simbolisme menuju realitas.

Dalam tema dari Ekaristi menuju ke kemartiran, Ignatius memberi teladan kepada umat agar mereka mau untuk saling berkurban satu sama lain demi terwujudnya persatuan. Bagi Ignatius, kemartiran harus didekati dan dipahami sebagai Ekaristi, yaitu kesempatan untuk berbagi atau berpartisipasi dalam kematian dan kebangkitan Yesus Kristus, yang menghendaki persatuan antara diriNya dengan seluruh umat-Nya. Bila dalamEkaristi, Kristuslah yang bersatu dengan kita, namun dalam kemartiran, kitalah yang berusaha untuk menyatu dengan Kristus. Itulah sebabnya, Lawyer mengatakan bahwa Ignatius melihat kemartirannya sebagai "Ekaristi yang terbalik" ${ }^{29}$ Ekaristi, dijadikan Ignatius sebagai sarana berpastoral dan pembelajaran bagi umat, agar merekapun siap untuk berkurban, menjadi martir, demi terwujudnya persatuan baik dengan Kristus maupun Gereja.

Tema dari simbolisme menuju realitas menjadi kesempatan bagi Ignatius untuk memberikan pembelajaran kepada umat, tentang perlunya Ekaristi bagi kebutuhan iman dan kasih. Dengan cerdik, Ignatius mengaitkan daging dan darah Yesus, yang ada dalam perayaan Ekaristi dengan iman, kasih dan Injil ${ }^{30}$. Ekaristi bukan hanya menumbuhkan iman dan kasih sebagai dasar kehidupan orang Kristiani, namun juga iman, kasih dan Injil diperlukan dalam menyambut Ekaristi. Untuk menyambut Ekaristi, umat harus mempersiapkan dan memperlengkapi diri dengan iman dan kasih, agar Ekaristi, daging dan darah Kristus sungguh dapat menjadi iman dan kasih yang memberi

dan hidup yang kekal, obat keabadian.

Nyata, bahwa pastoral Ekaristi dari Ignatius yang berorientasi pada kebutuhan praktis dari kehidupan jemaat. Kebutuhan tersebut dipadukan dengan ajaran iman, yang bersumber dari Injil dan tradisi para Rasul, sehingga menjadi aksi pastoral yang mampu diterima dan dihayati oleh jemaat pada masanya. Dari Ignatius, kita bisa belajar bahwa melalui pastoral Ekaristi yang terarah pada ajaran iman dan kebutuhan umat secara praktis, Gereja dapat mengadakan perubahan dan pembaharuan liturgi Ekaristi yang lebih berdaya sapa dan berdaya ubah bagi umat.

\subsection{Tanggapan}

Secara umum, surat-surat Ignatius dapat dilihat sebagai semacam dialektika teologi yang terus-menerus dan subur antara dua segi khas kehidupan Kristiani: struktur hierarkis komunitas Gereja dengan kesatuan dengan Allah dalam Kristus, yang mengikat semua orang beriman. Begitupun dengan reksa pastoral yang diperjuangkan Ignatius, yang memberi tempat pada kebutuhan umat sambil tetap mempertahankan ajaran iman dan tradisi dari para pendahulu. Dialektika ini jangan dipandang sebagai dikotomi yang saling bertentangan, namun sebagai sintesis yang saling memperkaya dan mampu menjawab kebutuhan umat akan persatuan mesra dengan Allah bersama Kristus dan persatuan dengan Gereja. Itulah sebabnya, Benediktus XVI menyatakan Ignatius sebagai "Guru Kesatuan", yang mengundang umat beriman dahulu dan sekarang, mengundang kita semua, untuk membuat sintesis antara konfigurasi dengan Kristus dan dedikasi kepada Gereja-Nya, sintesis antara communio dan missio. ${ }^{31}$

Di antara Bapa-bapa Gereja tidak ada seorang pun yang telah mengungkapkan keinginan akan persatuan dengan Kristus dan hidup dalam Dia dengan begitu mantap seperti Ignatius. ${ }^{32}$ Kerinduan yang tak tertahankan dari Ignatius akan persatuan dengan Kristus menjadi dasar bagi suatu "mistik persatuan" yang sejati dan asli. Dari semangat Ignatius, Gereja masa kini dapat belajar bagaimana menghayati persatuan mistik dengan Kristus melalui Ekaristi. Pengalaman mistik atau 
kesatuan dengan Tuhan, jauh lebih utama dibanding pengetahuan dan pemahaman akan rubrik/aturan. Penghayatan terhadap hidup mistik menjadi roh atau bahtera dalam mengarungi lautan kehidupan zaman sekarang yang dilingkupi oleh hempasan ombak sekularisme, terjangan semangat indvidual dan hedonisme yang tiada henti. Mengutip perkataan Karl Rahner: "Orang saleh, orang Kristen masa depan akan menjadi orang mistik .... atau ia tidak menjadi apa-apa lagi", ${ }^{33}$ penulis melihat bahwa Gereja masa depan adalah Gereja yang dilandasi oleh semangat mistik, ${ }^{34}$ yang bersumber dan berpuncak pada Ekaristi Kudus. Oleh karena itu, Gereja di Keuskupan Agung Jakarta atau di keuskupan lain di seluruh dunia hanya akan tetap memiliki masa depan apabila tetap memberi tempat pada pengalaman mistik kesatuan dengan Tuhan dalam Ekaristi.

Penulis juga melihat bahwa usaha dan pemikiran Ignatius dapat menginspirasi Gereja untuk memasuki kekayaan misteri Ekaristi yang tak pernah habis tergali. Penulis berharap agar Gereja pada zaman ini tidak hanya terpaku pada aturan/rubrik Ekaristi yang baku dan beku, namun mampu memberi semangat kepada umat untuk melangkah lebih jauh dengan mengali tradisi Gereja yang menjadi dasar/latar belakang dari tata peraturan Ekaristi itu, seraya berusaha menemukan rumusan teologi Ekaristi yang lebih sesuai dengan perkembangan sejarah.

Rumusan yang tetap mengindahkan ajaran iman dan tradisi namun juga kontekstual, terbuka terhadap konteks budaya, sosial dan kebutuhan umat. Dengan formulasi yang baru diharapkan perayaan liturgi, khususnya Ekaristi, dapat semakin berdaya sapa dan berdaya ubah bagi Gereja dan masyarakat. Untuk itu, dibutuhkan pengajaran dan persiapan yang terus menerus sehingga Gereja, seluruh umat beriman, dan bukan hanya kalangan "elite" atau teolog saja, dapat secara sadar berpartisipasi dalam menghidupi perubahan dan pembaharuan yang ada.

Akhirnya, studi komparasi teologi Ekaristi antara Ignatius dan Yohanes Paulus II, bukan saja mengantar penulis untuk menemukan kesinambungan pandangan dari kedua tokoh, yang nampak dalam kesamaan dan perkembangan gagasan mereka tentang teologi Ekaristi, namun juga mengantar pada sebuah pencerahan tentang bagaimana refleksi iman akan Ekaristi tidak dapat dilepaskan dari pengalaman iman Gereja perdana, masa lampau, yang menerangi perjalanan Gereja dalam menghidupi aneka pengalaman di masa kini, sambil terus menjadi penopang bagi pengharapan akan kehidupan Gereja di masa mendatang.

\section{Yakin Ciptamulya}

Rohaniwan dan Pemimpin Jemaat di Paroki St. Laurensius Serpong Utara, Alumnus Program Magister Teologi Universitas Sanata Dharma: yakin_ciptamulya@yahoo.com.

\section{CATATAN AKHIR}

Kongres Ekaristi bermula dari inisiatif awam Perancis yang bernama: Marie Tamisier (1834-1910). Gagasan awalnya adalah agar penghormatan kepada Sakramen Mahakudus bisa dilaksanakan secara meriah dan umum. Paus Leo XIII menyetujuinya, sehingga dibukalah Kongres Ekaristi yang pertama di Lille (1881).

2 Konsili Ekumenis Vatikan II, Konstitusi Dogmatis tentang Gereja: Terang Bangsa-bangsa (Lumen Gentium), 11.

3 Sebutan lain untuk dirinya adalah Theophorus yang berarti "Pemanggul Tuhan" dan menurut tradisi dia adalah salah satu dari anak-anak yang digendong dan diberkati Yesus.

C. Richardson, Early Christian Fathers, 74-75.

K. Lake, The Apostolic Fathers, I Clement, II Clement, Ignatius, Polycarp, Didache, Barnabas, 166.

$6 \quad$ F. D. Wellem, Ignatius dari Anthiokia, 137-139.

Benedictus XVI, Bapa-bapa Gereja, Hidup, Ajaran dan relevansi bagi manusia di zaman kini, 22.

8 Menurut tradisi, dikatakan bahwa pada masa pemerintahan Kaisar Trajanus, pada tahun yang ke-9, pada tahun 107, kaisar mengunjungi Antiokhia. Di Antiokhia kaisar mengancam akan membunuh semua orang yang tidak mau mempersembahkan kurban kepada dewa-dewa. Ignatius mempertahankan imannya dan menolak untuk mempersembahkan kurban kepada dewadewa. Ia menolak untuk menyangkal Kristus. Oleh karena itu, ia dijatuhi hukuman mati dengan diumpankan kepada singa di dalam Koloseum, Roma. Dengan tangan yang terantai serta dikawal oleh sepuluh orang tentara ia digiring ke Roma. “Izinkanlah aku meneladani Penderitaan Allahku!...”.“Aku gandum Tuhan, oleh gigi singa akan menjadi tanah yang baik bagi roti murni Kristus” (Roma 5-6). Bdk. "Dari Suriah menuju Roma saya bertarung siang malam dengan binatang buas, baik di darat maupun laut, saya diikat di tengah-tengah sepuluh macan tutul, yang adalah para tentara, mereka hanya bertambah buruk ketika saya memperlakukan mereka dengan baik.”

9 "Kurban Kristus dan kurban Ekaristi adalah kurban yang satu jua”, Bdk. Yohanes Paulus II, Ecclesia de Eucharistia no.12.

10 "Persekutuan Ekaristi juga meneguhkan Gereja dalam kesatuan sebagai tubuh Kristus, yang dipimpin oleh Sri Paus dan para Uskup, oleh ikatan pengakuan iman, sakramen, reksa pemerintahan Gereja dan persekutuan”. Bdk Yohanes Paulus II, Ecclesia de Eucharistia no.38.

11 Benedictus XVI, Bapa-bapa Gereja, Hidup, Ajaran dan Relevansi bagi Manusia di Zaman Kini, 22.

12 Efesus 7,2.

13 Magnesia 20,2.

14 E J. Lawyer, "Eucharist and Martyrdom in the Letters of Ignatius of Antioch”, 293.

15 Surat Rasul Paulus kepada jemaat di Efesus: "yang dibangun di atas dasar para rasul dan para nabi, dengan Kristus Yesus sebagai batu penjuru”(Efesus 2:20).

16 "You ought to allied and to respect him (bishop) as fully as you respect the authority of God the Father" (Magnesia 3). K. Lake, The Apostolic Fathers, 198-199.

17 "Wherever the bishop appers, there let the congregation be, just as wherever Jesus Christ is, there is the Catholic Chruch" (Smyrna 8,2). Bdk. "You cannot have a church without these" (Tralles 3). K. Lake, The Apostolic Fathers, 260-261; 214-215.

18 "As then the Lord was united to the Father and did nothing without him, neither by himself nor through the Apostles, so do you do nothing without the bishop and the presbyters” (Magnesia 7,1). K. Lake, The Apostolic Fathers, 202-203.

19 W. R. Schoedel, Ignatius of Antioch, a commentary on the Letters of Ignatius of Antioch, 21-22. 
20 "The Eucharist builds the Church and the Church makes the Eucharist” (EE 26/DC 4).

21 "Eucharist isthe flesh of our Saviour Jesus Christ, which suffered for oursins and which, in his goodness, the Father raised (from thedead)" (Smyrna 7,1). K. Lake, The Apostolic Fathers, 258259.

22 "Take care therefore, to participate in one Eucharist. For there isone flesh of our Lord Jesus Christ, and one cup which leads to unity to his blood; there isone altar, just as there is one bishop" (Philadelphia 4). K. Lake, The Apostolic Fathers, 242-243.

23 "You should obey the bishop and the presbytery with an undisturbed mind, breaking onebread, which is the medicine of immortality, theantidote that we should not die, but live for ever in Jesus Christ” (Efesus 20). K. Lake, The Apostolic Fathers, 194-195. Bdk.. Smyrna 7 dan Tralles 9.

24 "There is only one physician - of fleshyet spiritual, born yet unbegotten, God incarnate, genuine lifein the midst of death, sprung from Mary as well as God,first subject to suffering then beyond it in his second coming--Jesus Christ ourLord (Efesus 7,2). K. Lake, The Apostolic Fathers, Bdk. Smyrna 3.

25 "Gathering together, let there be one prayer, onepetition, one mind, one hope”. (Magnesia 7,1). K. Lake, The Apostolic Fathers, 202-203.

26 "Let there be nothing among you which capable of dividing you, but be united with the bishop" (Magnesia 6,1-2). K. Lake, The Apostolic Fathers, 201-203.

27 "Seek, then, to come together more frequently to give thanks and glory to God. For when you gather together frequently the powers of Satan are destroyed, and his mischief is brought to nothing,by the concord of your faith" (Efesus 13,1). K. Lake, The Apostolic Fathers, 186-187.

28 "It is, therefore, seemlyin every way to glorify Jesus Christ, who has glorifiedyou, in one obedient you will be unite in one idea,comment, and opinion” (Efesus 2) K. Lake, The Apostolic Fathers, 174-175.

29 "Ignatius sees his coming martyrdom as a 'Eucharist in reverse””. R. L. Fox, Pagan and Christians, 437, seperti dikutip oleh E J.Lawyer, Eucharist and Martyrdom in the Letters of Ignatius of Antioch, 286.

30 "Therefore, you must arm yourselves withgentleness and regain you strength in faith which is the flesh of the Lord and in lovewhich is the blood of Jesus Christ" (Tralles 8,1), "I want His blood which is incorruptible love” (Roma 7,3), "but your prayer to God willmake perfect, that I may attain the fate by which I have received mercy, since I havetaken refuge in the gospel as the flesh of Jesus" (Philadelphia 5,1). K. Lake, The Apostolic Fathers, 218-219, 234-235, 242-243.

31 Paus Benedictus XVI, Bapa-bapa Gereja: Hidup, Ajaran, dan Relevansi bagi Manusia di Zaman Kini, 25.

32 Ibid

33 Kata-kata terkenal dari Karl Rahner ini dikutip oleh penulis dari E. Martasudjita, “Ars Celebrandi: menuju Gereja Misktik yang semakin Ekaristis” dalam E. Martasudjita (ed.), Gereja yang Melayani dengan Rendah Hati, bersama Mgr. Ignatius Suharyo, 50.

34 Semangat mistik dalam pengertian ini dimaksudkan sebagai pengalaman kesatuan dengan Tuhan sebagai isi dan sisi batin dari pengalaman iman, dan bukan dalam arti pengalaman khusus, seperti misalnya pengalaman trans. Lih., Martasudjita, "Ars Celebrandi: menuju Gereja Misktik yang semakin Ekaristis”, 50.

\section{DAFTAR RUJUKAN}

Holmes, M.W, 2002, The Apostolic Fathers, Greek Text and English Translation, Michigan: Baker Book House, Grand Rapids.

Lake, K, 1912, The Apostolic Fathers, I Clement, II Clement, Ignatius, Polycarp, Didache, Barnabas, Harvard University Press, Cambridge, Massachusetts, London.
Richardson, C.C, 1953, Early Christian Fathers, Kentucky, Westminster: John Knox Press, Louisville.

Yohanes Paulus II, 2003, Ensiklik Ecclesia de Eucharistia, tentang Ekaristi dan Hubungannya dengan Gereja, diterjemahkan oleh Mgr. Anicetus B. Sinaga, OFM Cap, Jakarta: Dokpen KWI.

Dokumen Konsili Vatikan II

\section{Konstitusi Dogmatis “Lumen}

Gentium” tentang Gereja, diterjemahkan oleh

R.Hardawiryana, Jakarta: Dokpen KWI.

1993 Konstitusi "Sacrosanctum

Concilium” tentang Liturgi Suci, diterjemahkan oleh R.Hardawiryana, Jakarta: Dokpen KWI.

1993 Dekrit "Presbyterorum Ordinis" tentang Pelayanan dan Kehidupan para Imam, diterjemahkan oleh R.Hardawiryana, Jakarta: Dokpen KWI.

Pius XII, 1947, Ensiklik Mediator Dei (Pengantara Tuhan),

http://www.vatican.va/holy_father/pius_xii/en cyclicals/documents/hf_p-xii_enc 20111947_mediator-dei_en.html (18 Maret 2013)

Paulus VI, 1965, Ensiklik Mysterium Fidei (Misteri Iman),

http://www.vatican.va/holy_father/paul_vi/enc yclicals/documents/hf_p-vi_enc 03091965_mysterium_en.html (18 Maret 2013)

1968, Ensiklik Sollemnis Proffesio Fidei

(Profesi Iman Meriah), http://www.vatican.va/holy_father/paul_vi/mo tu_proprio/documents/hf_p -vi_motuproprio_19680630_credo_lt.html (18 Maret 2013)

Yohanes Paulus II, 1980, Surat Apostolik Dominicae Cenae (Perjamuan Tuhan), http://www.vatican.va/holy_father/john_paul_i i/letters/documents/hf_jpii_let_24021980_dominicae-cenae_en.html (12 Maret 2013)

1998 Surat Apostolik Dies Domini (Hari Tuhan), http://www.vatican.va/holy_father/john_paul_i i/apost_letters/documents/hf_jp-ii _ apl_05071998_dies-domini_en.html (12 Maret 2013)

2001 Surat Apostolik Novo Millennio Ineunte (Ambang Milenium Baru) http://www.vatican.va/holy_father/john_paul_i i/apost_letters/documents/hf_jpii_apl_20010106_novo-millennioineunte_en.html (16 Maret 2013) 2002 Surat Apostolik Rosarium Virginis Mariae (Rosario Perawan Maria) http://www.vatican.va/holy_father/john_paul_i i/apost_letters/documents/hf_jp- 
ii_apl_20021016_rosarium-virginismariae_en.html (16 Maret 2013)

Arinze, F, 2001, The Holy Eucharist, Indiana, Huntington: Our Sunday Visitor Publishing.

Barnard, L. W,1966, Studies in the Apostolic Fathers and their background, Oxford: Basil Blackwell.

Benedictus XVI, 2010, Bapa-bapa Gereja, Hidup, Ajaran dan relevansi bagi manusia di zaman kini, dari: 'The Father', Terj: Waskito SJ, Malang: Dioma.

Bouyer, L, 1960, The spirituality of the New Testament and the Fathers, Pueblo Publishing New York, Company.

Cross, F.L,1960, The Early Christian Fathers, London: Gerald Duckworth \& Co.LTD,

Syukur Dister, N, 2004, Teologi Sistematika 1 - Allah Penyelamat, Yogyakarta: Kanisius.

Hakh, S.B, 2003, Melihat Kemuliaan Tuhan, Jakarta: UPI STT Jakarta.

Havon, T, 1985, The Church, Message of The Fathers of The Church 4, Michael Glazier, Delware: Wilmington.

Kelly, J.N.D,1960, EarlyChristian Doctrines, New York: 2nd ed.

Jefford, C.N, 1996 ,Reading the Apostolic Fathers, Hendrickson Publishers, Massachusetts.

John Paul II, 1998, The Church: Mystery, Sacrament, Community, Pauline Books and Media, Boston.

Eddy Kristiyanto, A, 2008, Selilit Sang Nabi, Yogyakarta: Kanisius.

La Verdiere, E, 1996, The Eucaharist in the New Testament and the Early Church, Collegeville, Minnesota: A Pueblo Book, The Liturgical Press.

Liebeschuetz, J.H.W.G,1972, Antioch. City and imperial administration in the later Roman empire, London: Oxford Press.

Lightfoot, J.B, 1889, The Apostolic Fathers, Part II: S. Ignatius. S.Polycarp, $2 d$ ed.3 vols, Macmillan, London.

Lohse, B, 1978, Epochen der Dogmengeschichte, Stuttgart: Kreuz-Verlag; terjemahan Inggris: 1980, A Short History of Christian Doctrine: From the First Century to the Present, Philadelphia: Fortress Press.

Martasudjita, E, 2005, Ekaristi, Tinjauan Teologis, Liturgis, dan Pastoral, Yogayakarta: Kanisius. 2012 Ekaristi, Makna dan Kedalamannya bagi Perutusan di Tengah Dunia, Yogyakarta: Kanisius.

Maxwell-Stuart, P.G, 2006, Chronicle of the Popes, London: Thames \& Hudson.

Nichols, A,1991, The Holy Eucharist: From the New Testament to Pope John Paul II, Dublin: Veritas.

O’Conor, J.T, 2005, The Hidden Manna: A Theology of the Eucharist, San Francisco, CA: Ignatius Press.

Quasten, J, 1950, Patrology. 3 vols, Westminster.
Rapp, C, 2005, Holy Bishops in Late Antiquity, The Nature of Christian Leadership in an Age of Transition, Berkeley, Los Angeles, and London: University of California Press.

Rankin, D.I, 2006, From Clemen to Origen, The Social and Historical Contexs of The Church Fathers, Hampshire, England: Ashgate Publishing Limited.

Sabato, S - Carigi, A, 1983, Santo Maximilianus Maria Kolbe, Kesatria Maria yang tak bernoda, Yogyakarta: Kanisius.

Schoedel,W. R,1985, Ignatius of Antioch, a commentary on the Letters of Ignatius of Antioch. Diedit oleh Helmut Koester, Augsburg: Fortress Press.

Stourton,E, 2006, John Paul II: Man of History, London: Hodder \& Stoughton.

Tenney, M.C, 1995, Survei Perjanjian Baru, Malang, Gandum Mas.

Vonier, A,2004, A Key to the Doctrine of the Eucharist, San Fransisco, Ignatius Press.

Wallace D.S. - Hadrill, 1982, Christian Antioch, A Study of early Chiristian thought in the East, Cambridge: Cambrigde University Press.

Wellem, F. D,1999, Ignatius dari Anthiokia, dalam: "Riwayat Hidup Singkat Tokoh-Tokoh dalam Sejarah Gereja”, Jakarta: BPK Gunung Mulia.

Williams, G.H, 1981, The Mind of John Paul II: Origins of His Thought and Action, New York: Seabury Press.

Willis, J.R (ed), 1966, The Church, The Teaching of The Church Fathers, Montreal: Palm Publisher.

Zahn, T, 1873, Ignatiusvon Antiochien, Gotha: Perthes. Zizioulas, J.D, 2001, Eucharist, Bishop, Church: The unity of The Church in The Divine Eucharist and The Bishop during The First Three Centuries, Brookline, Massachusetts: Elizabeth Theokritoff (trans), Holy Cross Orthodox Press.

Connell, Cardinal D, 2005,"Preface” dalam McEvoy, James - Hogan SSC, Maurice (ed), The Mystery of Faith: Reflections on The Encyclical Ecclesia de Eucharistia, Irish, Dublin: The Columba Press.

Farey, C, 2005, “At the School of Mary, 'Woman of the Eucharist", dalam McEvoy, James Hogan SSC, Maurice (ed), The Mystery of Faith: Reflections on The Encyclical Ecclesia de Eucharistia, Irish, Dublin: The Columba Press.

Fields, S.M, 2007, "John Paul II and the Eucharist: Sacrament and Sacrifice of Freedom” dalam McDermott, M. - Gavin, John (ed), John Paul II on The Body, Human Eucharistic Ecclesial, Philadelphia: St. Joseph's University Press,.

Fiore, B.E, 2007, "The Marian Eucharist, Aesthetics, and Covenant” dalam McDermott, M. Gavin, John (ed), John Paul II on The Body, Human Eucharistic Ecclesial, Philadelphia: St. Joseph's University Press. 
Gorevan, P, 2005, “A People of Priests” dalam McEvoy, James - Hogan SSC, Maurice (ed), The Mystery of Faith: Reflections on The Encyclical Ecclesia de Eucharistia, Irish, Dublin: The Columba Press,.

Johanny, R, "Ignatius of Antioch", dalam Willy Rordorf and Others (ed), The Eucharist of the early Christians, New York: Pueblo Publishing.

Klawiter, F.C, 2007,“The Eucharist and Sacramental Relism in the Thought of St. Ignatius of Antioch”, Studia Liturgica, An International Ecumenical Review for Liturgical Research and Renewal.

La Verdiere, E,1993,“The Eucharist, Sacrament of the Transformation of the World”, Emmanuel Magazine 99.

Lawyer, E J, 1991,"Eucharist and Martyrdom in the Letters of Ignatius of Antioch", dalam AnglicanTheological Review 73.

Martasudjita, E, 2009, "Ars Celebrandi: menuju Gereja Misktik yang semakin Ekaristis” dalam Martasudjita, E. (ed),Gereja yang Melayani dengan Rendah Hati, bersama Mgr. Ignatius Suharyo, Yogyakarta: Kanisius.

McDemott, J.M, 1993,“The Theology of John Paul II: A Response," dalam McDemott, John. M, (ed), The Thought of Pope John Paul II: A Collection of Essays and Studies, Rome: Gregorian.

McPartlan, P,2005, “Ut Unum Sint: Eucharist and Ecumenism” dalam McEvoy, James - Hogan SSC, Maurice (ed), The Mystery of Faith: Reflections on The Encyclical Ecclesia de Eucharistia, Irish, Dublin, The Columba Press.

Moloney, R, 2005 “The Eucharist Builds the Church" dalam McEvoy, James - Hogan SSC, Maurice (ed), The Mystery of Faith: Reflections on The Encyclical Ecclesia de Eucharistia, Irish, Dublin: The Columba Press.
McEvoy, James - Hogan SSC, Maurice (ed), The Mystery of Faith: Reflections on The Encyclical Ecclesia de Eucharistia, Irish, Dublin: The Columba Press.

Rius-Camps, J,1979,“The four Authentic Letters of Ignatius, the Martyr”,PontificiumInstitutum Orientalium Studiorum, Rome.

Spence, M,2005,“The Priest Acting in persona Christi” dalam McEvoy, James - Hogan SSC, Maurice (ed), The Mystery of Faith: Reflections on The Encyclical Ecclesia de Eucharistia, Irish, Dublin, The Columba Press.

Steck, C.W,2007, "In Union with the Paschal Mystery: The Eucharist and Suffering in the Thought of John Paul II” dalam McDermott, M. - Gavin, John (ed), John Paul II on The Body, Human Eucharistic Ecclesial, ed. John M. McDermott dan John Gavin, Philadelphia: St. Joseph’s University Press.

Walsh, L, 2005, "The Presence of the Mystery of Christ in the Broken Bread” dalam McEvoy, James Hogan SSC, Maurice (ed), The Mystery of Faith: Reflections on The Encyclical Ecclesia de Eucharistia, Irish, Dublin: The Columba Press.

Woodhall, J.A, 1972, "The Eucharistic Theology of Ignatius of Antioch”, dalam Communio 5.

Departemen Pendidikan dan Kebudayaan, 1988, Kamus Besar Bahasa Indonesia (KBBI), Departemen Pendidikan dan Kebudayaan, Jakarta: Balai Pustaka.

EkoEndarmoko, 2006, Tesaurus Bahasa Indonesia, Jakarta: Gramedia Pustaka Utama.

Kamus elektronik, 1999, Concise Oxford DictionaryTenth Edition. Oxford University Press (C).

Parrinder,G, 2000, The Routledge Dictionary of Religious \& Spiritual Quotations, London: Routledge,.

Pusat Pembinaan dan Pengembangan Bahasa, 2007: Pedoman Umum Ejaan Bahasa Indonesia yang Disempurnakan, Yogayakarta: Indonesiatera.

Poerwadarminta,W. J. S, Kamus Umum Bahasa Indonesia, Jakarta: Balai Pustaka. 